\title{
LIGATURE OF PATENT DUCTUS ARTERIOSUS
}

\author{
BY \\ GEOFFREY BOURNE \\ Received February 6, 1945
}

The effect of ligation on infection of the patent ductus has been admirably summarized from the surgical point of view by my colleague, Mr. O. S. Tubbs (1944). His paper, which gives a valuable account of the anatomy, physiology, and pathology of the ductus arteriosus, is based upon nine infected cases, eight of which were treated by us in collaboration. The purpose of the present paper is to discuss certain medical aspects of these cases and of two additional non-infected cases, also submitted to operation. Details of the individual infected cases are already published in Mr. Tubb's paper, and are referred to here by the same numbers as those used in that paper and in that of Bourne, Keele, and Tubbs (1941).

\section{INFECTĘD CASES}

Dr. Keele's case, Case 1 of our series (Bourne, Keele, and Tubbs, 1941) was the first infected case recorded that was cured by ligature of the ductus arteriosus. The date of the operation was December 5, 1939. Of the first five patients of our series, four are alive and well, from five to three years after the operation, with no recurrence of symptoms, of infection, or of cardiac disability. The permanent value of the operation is thus proved.

The infecting organism in Case 1 was $H$. para-influenzo, and in seven other cases it was Streptococcus viridans. In one case (Case 8) the infection was apparently mixed, Staphylococcus aureus and Streptococcus viridans.

Although the number of cases is not large, certain observations, even if made in a single case, are so significant as to be worth recording, and may even form the basis of legitimate deductions. The extent to which these deductions are true, and the proportion of cases in which the observed phenomenon occurs must, of course, be determined by the study of a much larger number of cases.

Heart Size. The late result of ligature on the heart size is well shown in the X-ray photographs taken in Case 2 (Fig. 1). The first picture, dated October 10, 1940, shows an enlarged heart, the transverse diameter of the heart measuring $14.25 \mathrm{~cm}$. and that of the thorax 24.75 $\mathrm{cm}$; it also shows typical enlargement of the pulmonary conus. The second picture, dated March 23, 1942, shows the transverse diameter of the heart to be $12.25 \mathrm{~cm}$. and that of the thorax $24.75 \mathrm{~cm}$; ; the heart contour has become normal and the conus is no longer enlarged. This shows that ligature of the patent ductus can cause a reduction in heart size similar to that observed by Drury (personal communication) in animals in which an experimental arterio-venous aneurysm had been produced, and by Hitzig (1935) after ligature of arteriovenous aneurysm in man.

Thrill and Murmur. The classical thrill and murmur are generally ascribed to the rapid flow of blood from the aorta to the pulmonary artery. This presumably occurs when the aortic pressure is higher, i.e. during systole and early diastole. Compression of the patent ductus during operation obliterates the thrill in nearly every case, and this largely confirms the above theory of its causation. The following observations suggest that this explanation is not complete. Firstly, in Case 2, application of one ligature only reduced, but did not abolish, the thrill; this disappeared only after a second ligature had obliterated more of the lumen of the ductus. Secondly, in the same case, the diastolic murmur at first disappeared, 


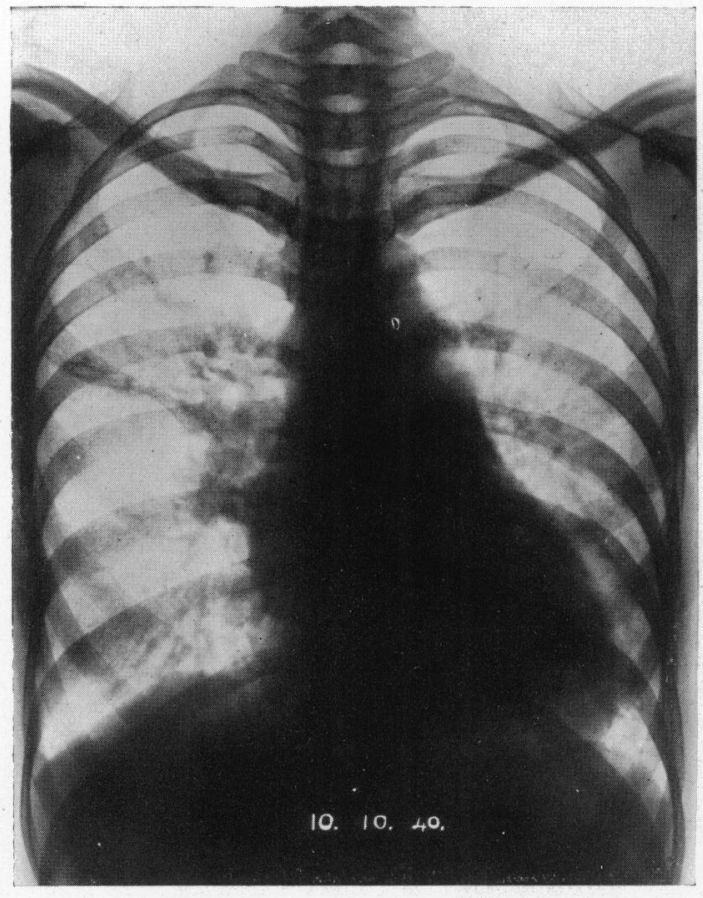

A

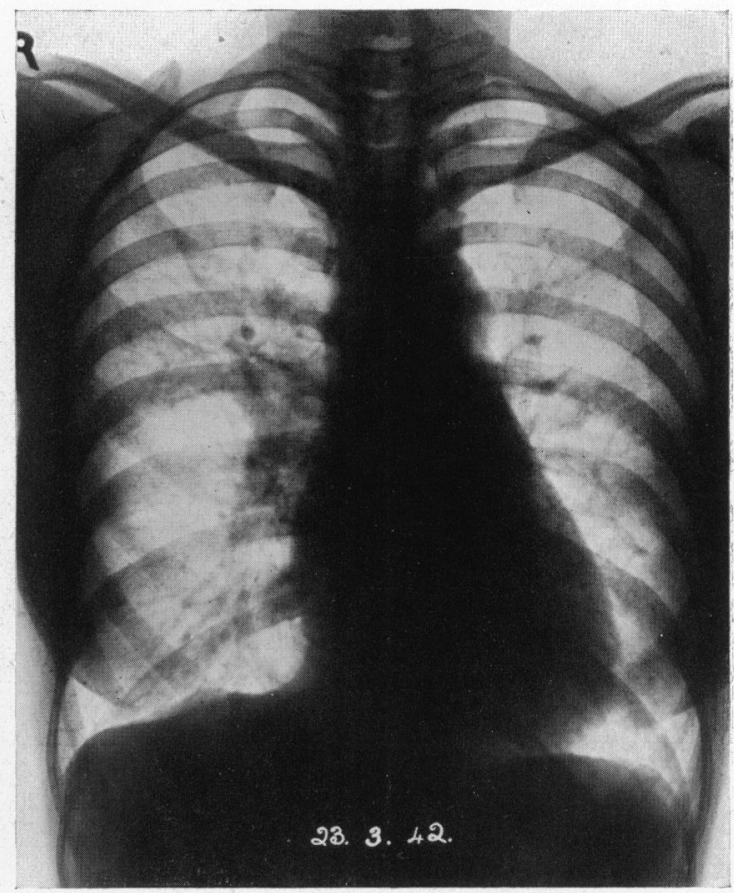

B

Fig. 1.-Reduction in size of the heart after ligature of the patent ductus arteriosus (m.t.d. reduced from $14 \cdot 25$ to $12 \cdot 25 \mathrm{~cm}$.). (A) $10 / 10 / 40$. (B) $23 / 3 / 42$.

but returned, much less in volume, seventeen months after ligature, although the transverse diameter of the heart had diminished by $2 \mathrm{~cm}$., and although the blood pressure remained perfectly normal (Fig. 1). Thirdly, in Case 4, the diastolic murmur disappeared for two weeks and then fully returned; yet, at the post-mortem examination seven weeks after operation, the pulmonary end of the ductus was found to be so blocked by a massive clot that water injected into the aorta failed to pass. There was, however, an aneurysm of the ductus, patent to the aorta and $3 \mathrm{~cm}$. in diameter. Finally, Shirley Smith's observations (1929) on cases of patent ductus in infants, in which the typical thrill and murmur were absent during life, may be relevant to this problem.

The general deduction would appear to be that, although the thrill and murmur are largely caused in the usually accepted fashion, this is not the whole explanation. Patency of the ductus may occur without these signs, and these signs may be present without patency, although such conditions are exceptional.

The Blood Pressure. Immediately after ligature, a great rise in the diastolic and a lesser rise in the systolic blood pressure was observed. The figures for the changes in diastolic pressure (in mm. of mercury) in the first six cases were as follows: Case 1, from 60 to 120; Case 2, from 40 to 122; Case 3, from 58 to 108; Case 4, from 56 to 90; Case 5, from 64 to 98 ; Case 6, from 52 to 102 ; the average rise being from 55 to 107 . This diastolic increase above normal may last for some weeks (Bourne, 1941), and therefore it is probably due to factors other than the increased blood volume. The cardiac hypertrophy, or an increased peripheral vascular tone, or both, may be causative factors. An associated state of temporary renal failure has. been noted (Bourne, 1941). The sudden blood pressure change did not cause symptoms in any of the patients.

The Effect of Ligature upon Infection of the Ductus. Ligature is the only proved curative measure available. Without it the condition is usually fatal. Only two cases of recovery without treatment by ligature are on record (Chester, 1937; and Touroff and Tuckman, 1942). Of the present series of nine infected cases treated by ligature six are alive and well, from five to nearly two years after the operation. The results obtained in Case 5 demonstrate that ligature of the ductus can, of itself, bring about the disappearance of the infection, 
for in this case all other forms of treatment were withheld. Seven days after ligature, the patient became completely afebrile, and the blood culture, which had previously been positive, showing the presence of Streptococcus viridans, became negative and remained so.

The Effect of Chemotherapy. The results obtained by the use of drugs were disappointing. In one case only (Case 2), sulphapyridine sterilized the blood and removed the fever for the twelve day period preceding operation. In Case 1 , where infection was due to $H$. parainfluenzo, sulphapyridine was ineffective. In six cases of infection by Streptococcus viridans, sulphanilamide, sulphapyridine, sulphathiazole, sulphadiazine, and sulphamezathine given in full doses produced no effect. One or more of these drugs was tried in each case. In one case (Case 8) infected by Staphylococcus aureus sulphathiazole failed.

This suggests that no advantage is obtained by instituting chemotherapy before operation if the condition of the patient is reasonably good. Chemotherapy, however, should be used to modify the severity of the toxæmia, before operation, in patients who are critically ill. It is also of value after operation, when infection persists. Infection may persist at the pulmonary end of the ductus, or in metastic and embolic infection in the lung. Chemotherapy, clearly, should be tried also if the post-operative fever is due to infection of the mitral or aortic cusps, although here the effect is problematical.

Prognosis in Cases Treated by Ligature. The ultimate prognosis is good, considering the seriousness of the condition. Experience in the surgeon and skill in the anæsthetist are, of course, vitally important. From the small series of cases here recorded certain ideas concerning prognosis suggest themselves.

The degree of illness is a clinical matter, and is hard to evaluate scientifically. But in Case 3 the patient was desperately ill, and by ordinary criteria was an unsuitable subject for a surgical operation. None the less this was decided upon, and the patient made a good recovery. The comparatively small risk of operation in these ill and toxic patients is also stressed by the fact that no death occurred on the table. One patient died 45 minutes after the operation. The other two fatal cases, both of whom had severe secondary pulmonary sepsis from infected pulmonary emboli, survived the operation by seven weeks and by four months respectively.

It may be significant that Cases 4 and 7 had marked cardiac enlargement ; both died. In Case 9, the other fatal case, the heart was only slightly enlarged, and infection of the aortic valve was present.

Pulmonary embolism and infarction in this condition is of two varieties, that occurring from the growing vegetations, and that resulting from the fragmentation of clots or vegetations during the healing process. The former occurs before, and the latter after operation. Pre-operative embolism, with pleurisy, either with radiological change or visible or palpable at operation, was present in seven of the nine infected cases. Its presence, therefore, does not seem to influence the prognosis. Post-operative embolism in convalescence is common and is equally free from serious danger.

In two of the three fatal cases, an aneurysm of the pulmonary artery $(3 \mathrm{~cm}$. in diameter in Case 4, and $1.5 \mathrm{~cm}$. in diameter in Case 9) together with multiple pulmonary infarcts was present. In two fatal cases, left-sided endocarditis was found at autopsy, aortic endocarditis in Case 7, and mitral and aortic endocarditis in Case 9.

The increased virulence of infective endocarditis in children also seems to influence the outlook in the case of this lesion. The two youngest patients, aged 10 and 15 years, died.

These factors must all be remembered in estimating the possible result of operative treatment.

\section{Ligature OF NON-INFECTED CASES}

A large number of uninfected cases have been treated by ligature and have been reported by several authors. Indications for this operation would seem to be mainly:

(1) the anticipation of subsequent infection,

(2) the threat of heart failure, or

(3) in children, the failure to grow normally.

It is highly probable that the risk of subsequent infection can be prevented by this operation. 
The figures given by Maud Abbott (1936), showing that infection developed in 29 per cent of 73 cases over the age of two years, suggest that the chance of subsequent infection is great. It is also true that the operative risk is less in the uninfected cases, the uninfected ductus being less fragile. On the other hand, the procedure is not without danger. Future developments in chemotherapy, or treatment by penicillin, may strengthen the conservative attitude of watching such cases and reserving surgical treatment until the actual onset of infection. This is the writer's policy in this matter at present. [Since the date of writing one case, treated with penicillin, before operation, became afebrile in 36 hours.]

The two following cases have not been described previously. In one, a woman of 24 years of age, heart failure was present. The history was that she had always been short of breath on exertion, and that this had been increasing slowly up to the point when she would have to stop after climbing about five steps. Orthopnœa had also been present. Three months previous to operation, œdema of the feet and legs had appeared and had been increasing. The lesion was considerable, for the heart was large. The heart diameter was $15 \mathrm{~cm}$. and that of the chest $30.5 \mathrm{~cm}$.; the blood pressure was $140 / 54$. Since operation she has been better than ever before in her life. During this period of one year and seven months she has done war work for nine hours daily in a factory, often including Sundays. She was able to remain at work for six months of pregnancy without symptoms. She had previously had two children, but her life had been that of a partial invalid. Thus, ligature of the ductus would seem to be indicated for the relief of early congestive failure.

The other case was that of a child of nine years. She was symptomless, but was undeveloped for her age compared with two older brothers, and the heart was a little enlarged. Her father, a doctor, had a lively realization of the risk of infection. In this combination of circumstances operation was decided upon. Unfortunately, the ductus was of the stoma or " window" type, having no length at all. This rendered ligature impossible. The danger of the ductus being of the stoma or "window" type must be taken into account in assessing the operative outlook, either clinically or in discussion with patients or relatives both in infected and in non-infected cases.

\section{CONCLUSIONS}

In infected cases of patent ductus arteriosus, successful ligature of the ductus brings about a lasting cure.

In non-infected cases (of which I have less experience) it may be most successful even at the stage when heart failure is developing.

\section{REFERENCES}

Abbott, Maud, E. (1936). Atlas of Congenital Heart Disease, Amer. Heart Assn., New York. Bourne, G. (1941). Brit. Heart. J., 3, 228.

Bourne, G., Keele, K. D., and Tubbs, O. S. (1941). Lancet, 2, 444.

Chester, W. (1937). Amer. Heart J., 13, 492.

Drury, A. (personal communication).

Hitzig, W. M., and Master, A. M. (1935). J. Mount Sinai Hosp., 1, 269.

Shirley. Smith, K. (1929). Arch. Dis. Childhood, 4, 330.

Touroff, A. S. W., and Tuckman, L. R. (1942). Amer. Heart J., $23,857$.

Tubbs, O. S. (1944). Brit. J. Surg., 32, 125, 1. 